Provided for non-commercial research and education use. Not for reproduction, distribution or commercial use.

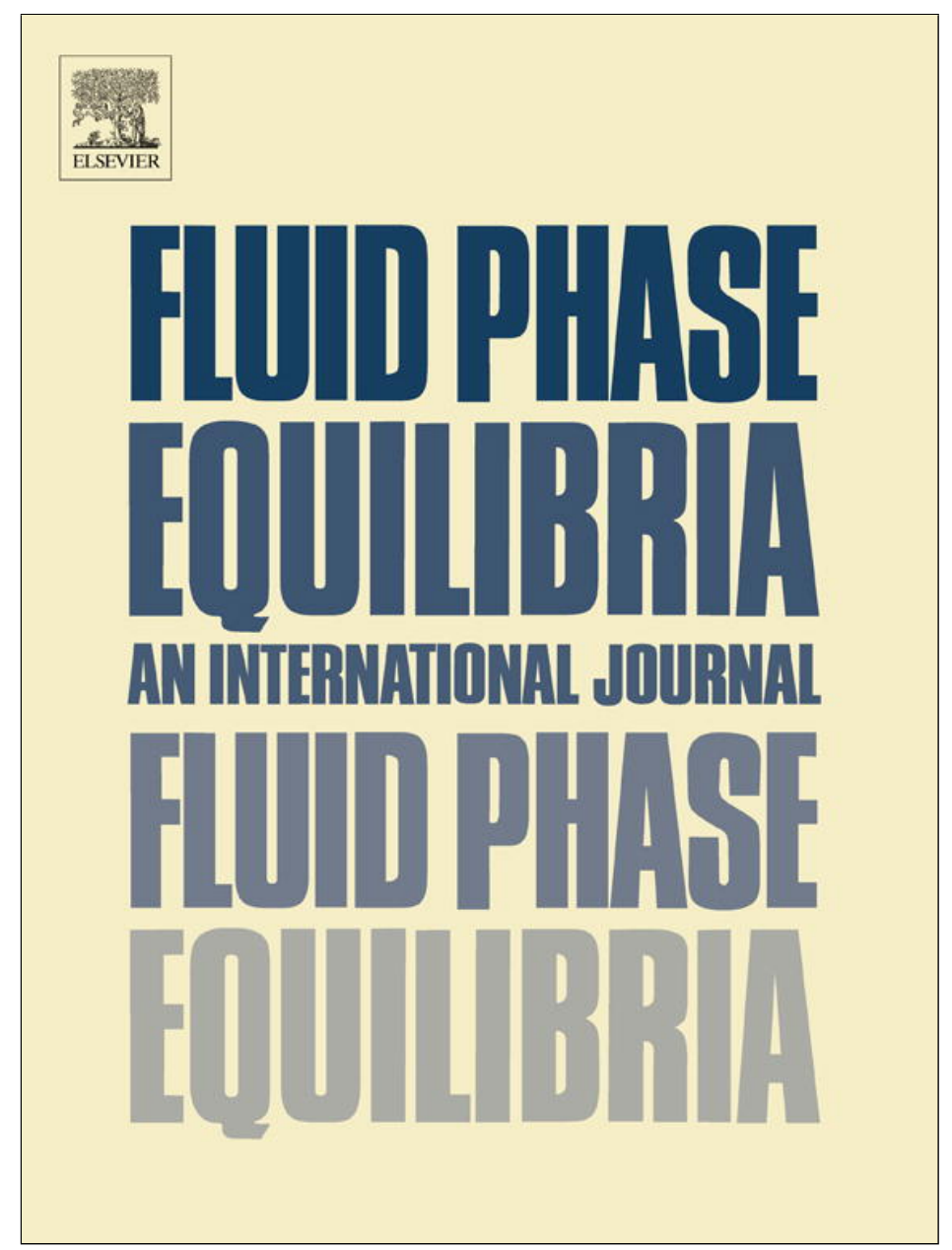

This article appeared in a journal published by Elsevier. The attached copy is furnished to the author for internal non-commercial research and education use, including for instruction at the authors institution and sharing with colleagues.

Other uses, including reproduction and distribution, or selling or licensing copies, or posting to personal, institutional or third party websites are prohibited.

In most cases authors are permitted to post their version of the article (e.g. in Word or Tex form) to their personal website or institutional repository. Authors requiring further information regarding Elsevier's archiving and manuscript policies are encouraged to visit:

http://www.elsevier.com/authorsrights 


\title{
Solubilities of 3-acetylpyridine in supercritical carbon dioxide at several temperatures and pressures: Experimental and modeling
}

\author{
Bely Agustin ${ }^{\mathrm{a}, \mathrm{b}}$, Shi-Yow Lin ${ }^{\mathrm{b}}$, Alfin Kurniawan ${ }^{\mathrm{a}}$, Yi-Hsu Ju ${ }^{\mathrm{b}, * *}$, Felycia Edi Soetaredjo ${ }^{\mathrm{a}, \mathrm{b}}$, \\ Suryadi Ismadji ${ }^{\text {a,* }}$
}

a Department of Chemical Engineering, Widya Mandala Surabaya Catholic University, Kalijudan 37, Surabaya 60114, Indonesia

${ }^{\mathrm{b}}$ Department of Chemical Engineering, National Taiwan University of Science and Technology, 43 Sec. 4 Keelung Road, Taipei 106, Taiwan

\section{A R T I C L E I N F O}

\section{Article history:}

Received 9 December 2012

Received in revised form 14 June 2013

Accepted 18 June 2013

Available online 27 June 2013

\section{Keywords}

3-Acetylpyridine

Solubility

Density-based model

Equations of state

Phase equilibria

\begin{abstract}
A B S T R A C T
3-Acetylpyridine (methyl 3-pyridyl ketone) is one of the important compounds to impart flavor and fragrance in various food products. In this work, the solubility data of 3-acetylpyridine in supercritical carbon dioxide $\left(\mathrm{SC}_{-} \mathrm{CO}_{2}\right)$ were experimentally measured at several temperatures $(313.15 \mathrm{~K}, 323.15 \mathrm{~K}, 333.15 \mathrm{~K}$, and $343.15 \mathrm{~K}$ ) and pressures from $10 \mathrm{MPa}$ to $26 \mathrm{MPa}$ under static mode. The experimental solubilities over the measurement range were correlated using Chrastil and Del Valle and Aguilera density-dependent models while phase equilibrium behavior of the studied system was interpreted by Peng-Robinson equation of state (PR-EoS) incorporated with quadratic and Stryjek-Vera mixing rules. The agreement between the model predictions and experimental solubilities was assessed in respect to root-mean-square deviation (RMSD) and consistency of physical meaning of model parameters. Concerning phase equilibria of the studied supercritical system, PR-EoS incorporated with quadratic mixing rule was superior to PR-EoS incorporated with Stryjek-Vera mixing rule and capable to describe the dependency of adjustable binary interaction parameters with temperature.
\end{abstract}

(c) 2013 Elsevier B.V. All rights reserved.

\section{Introduction}

Pyridines represent a class of heterocyclic organic compounds that significantly contribute to the organoleptic properties of many food products. Of particular interest is 3-acetylpyridine (or methyl 3-pyridyl ketone), a colorless to yellowish clear liquid with peanutlike odor and can be naturally found in roasted hazelnuts/filberts and cocoa [1,2]. This compound is frequently used as a flavoring agent and to impart a distinctive scent in the baked goods, candies, puddings, and non-alcoholic beverages. The isolation techniques of 3-acetylpyridine from grounded roasted hazelnuts/filberts are mostly conducted by steam or molecular distillation processes [2]. Denaturation risk and low purity of the final product are two main disadvantages of those conventional processes, which drive the searching of alternative techniques to appropriately isolating this heat-labile compound.

Over the past decades, supercritical fluid extraction has gained increasing awareness as a promising method for isolating valuable bioactive compounds from various natural products for

\footnotetext{
* Corresponding author. Tel.: +62 31389 1264; fax: +62 313891267.

** Corresponding author. Tel.: +8862 273766 12; fax: +8862 27376644

E-mail addresses:yhju@mail.ntust.edu.tw(Y.-H.Ju), suryadiismadji@yahoo.com, a1f1n_kwn@yahoo.com (S. Ismadji).
}

pharmaceutical and food industries. This technique is considered greener compared to conventional extraction processes which usually involve the use of harmful organic solvents and fairly high operating temperature [3]. Another uniqueness of supercritical fluid extraction is that this process generates zero waste because the solvent is completely recyclable and can be conducted at nearlyambient temperature, thus ensuring the stability and quality of the final product. To date, carbon dioxide $\left(\mathrm{CO}_{2}\right)$ is the most widely used supercritical solvent due to its practical advantages such as non-toxic, non-flammable, and non-explosive, environmentally acceptable, cheap, low critical temperature ( $T_{c}$ of $\left.304.2 \mathrm{~K}\right)$, and easily obtained in ultra high purity $[3,4]$.

The information about solubilities of the compounds of interest in supercritical solvents at wide range of pressures and temperatures is of crucial importance for the process design and optimizing supercritical-based processes, particularly for industrial practice. To the best of our knowledge, there is no previous report available in the literatures about the solubilities of 3acetylpyridine in supercritical carbon dioxide. In the present work, the solubilities of 3-acetylpyridine in supercritical carbon dioxide is measured in a static operation mode at four temperatures ranging from $313.15 \mathrm{~K}$ to $343.15 \mathrm{~K}$ and several pressures range between $10 \mathrm{MPa}$ and $26 \mathrm{MPa}$. The experimental solubility data were modeled with Chrastil and Del Valle and Aguilera semi-empirical densitydependent correlations and Peng-Robinson cubic equation of state 
Table 1

Some chemical information about 3-acetylpyridine compound.

\begin{tabular}{ll}
\hline Name & \\
\hline CAS number & 3 -Acetylpyridine \\
Purity & $350-03-8$ \\
Physical appearance & $\geq 98 \%$, food grade \\
Organoleptic & Clear, dark yellow liquid \\
Empirical formula & Nutty; sweet \\
Molecular mass & $\mathrm{C}_{7} \mathrm{H}_{7} \mathrm{NO}$ \\
Boiling point & $121.14 \mathrm{~g} /$ mol \\
& $493.15 \mathrm{~K}$ \\
\hline
\end{tabular}

incorporated with quadratic and Stryjek-Vera mixing rules was applied to interpret phase equilibria of the studied system.

\section{Materials and methods}

\subsection{Chemicals}

Food grade 3-acetylpyridine was purchased from Sigma-Aldrich chemical company, Singapore without further purification. Some information about this flavoring compound are given in Table 1. Food grade carbon dioxide (99.98\% pure) was supplied by a local gas company in a deep tube liquid supply cylinder. Ethanol was obtained from Sigma-Aldrich with a purity of $96 \%$ and used as a liquid medium for trapping 3-acetylpyridine.

\subsection{Solubility measurements}

The schematic of experimental set-up for static measurements of 3-acetylpyridine solubilities in supercritical carbon dioxide is displayed in Fig. 1. The supercritical apparatus consists of a vacuum pump (GAST DOA-P504-BN), a calibrated wet gas flow meter (ZEALDM3B), a high pressure liquid metering pump with two reciprocating pistons (Eldex AA-100-S-2), a pressure transducer (Druck PTX 611) connected to digital process indicator (Druck DPI 280), a thermostated oven (Memmert UM400), and a $150 \mathrm{ml}$ high pressure double-ended sample cylinder $(17.22 \mathrm{~cm}$ long $\times 4.85 \mathrm{~cm}$ i.d.). All fittings and tubings are made of 316SS-grade stainless steel (Swagelok, USA). The maximum working temperature and working pressure of the system is $423.15 \mathrm{~K}$ and $40 \mathrm{MPa}$, respectively. The measurement uncertainties were $\pm 0.01 \mathrm{MPa}$ for pressure and $\pm 1 \mathrm{~K}$ for temperature.

Briefly, a known amount of cotton $( \pm 1 \mathrm{~g})$ was wetted with liquid 3-acetylpyridine $( \pm 1 \mathrm{ml})$ and packed into the sample cylinder. Both ends of the cylinder were fitted with sintered stainless steel filter discs $(50 \mu \mathrm{m})$ to prevent any entrainment loss. Then, the system was evacuated with a vacuum pump. The evacuated system was heated to predetermined temperatures. Subsequently, liquid $\mathrm{CO}_{2}$ was compressed and delivered passing through the tubing to the sample cylinder at a constant flow rate of $10 \mathrm{ml} / \mathrm{min}$ (measured at 6.8 MPa and $303.15 \mathrm{~K}$ ) until desired pressures reached. The system pressure was monitored real-time and the system temperature was controlled by a built-in PID-type temperature controller of the oven to maintain isobar and isothermal conditions. Preliminary experiments show that equilibrium was established within $2 \mathrm{~h}$. The equilibrated supercritical phase was thereafter released from the sample cylinder at the same condition by fresh $\mathrm{CO}_{2}$ into a receiving vial containing some volume of $96 \%$ ethanol to completely separate 3 -acetylpyridine and carbon dioxide. A vent needle was mounted

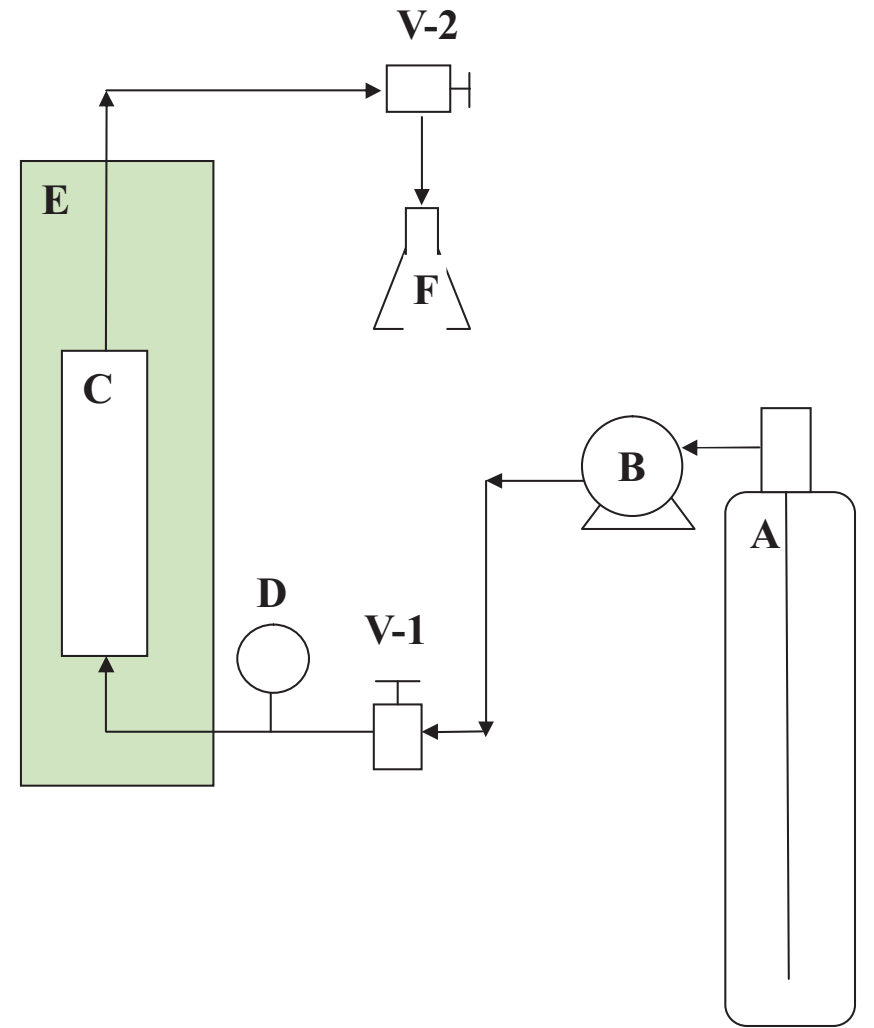

Fig. 1. Schematic of experimental set-up for solubility measurement in high pressure condition (dip tube liquid $\mathrm{CO}_{2}$ supply cylinder (A); high pressure liquid metering pump (B); high pressure equilibration cylinder (C); pressure transducer (D); thermostated oven $(E)$; receiving vial $(F)$; valve - $(\mathrm{V}-1)$ inlet line, $(\mathrm{V}-2)$ outlet line).

on the receiving vial to allow the expanded gas to exit and total volume of solute-free ambient gas was measured with a calibrated wet gas flow meter $( \pm 0.05 \mathrm{~L})$ at a known pressure and temperature. Care was taken to prevent sample precipitation during the decompression of high-pressure stream by gently heating the discharge line and flushing with fresh $\mathrm{CO}_{2}$. The ethanol containing 3-acetylpyridine was then analyzed on a Shimadzu GC-2014 gas chromatograph under prescribed condition.

The quantification of 3-acetylpyridine concentration in ethanol was conducted by means of gas chromatography analysis, adopting operation condition reported by Kulshreshtha and Moldoveanu [5]. The gas chromatograph was equipped with a split/splitless injector, an Agilent narrowbore DB-Wax capillary column $(30 \mathrm{~m} \times 0.25 \mathrm{~mm}$; $0.25 \mu \mathrm{m}$ ) as the stationary phase, and a flame ionization detector (FID). The injection volume was $1 \mu \mathrm{l}$ in splitless mode. The injector and FID temperature was operated at $280^{\circ} \mathrm{C}$ and $300^{\circ} \mathrm{C}$, respectively. Highly pure helium (99.98\%) was employed as the carrier gas at pressure of $134.9 \mathrm{kPa}$ and a column flow of $2 \mathrm{ml} / \mathrm{min}$. The initial column oven temperature was set at $40^{\circ} \mathrm{C}$ for $5 \mathrm{~min}$, then ramped to $110^{\circ} \mathrm{C}$ with a heating rate of $4{ }^{\circ} \mathrm{C} / \mathrm{min}$ and increased to $230^{\circ} \mathrm{C}$ at $10^{\circ} \mathrm{C} / \mathrm{min}$ and held for $5.5 \mathrm{~min}$. Total program time was $40 \mathrm{~min}$. Identification of 3-acetylpyridine peak in the samples was conducted by matching retention time with that previously obtained by the injection of authentic standard. Calibration curve was prepared by injecting five standard solutions of 3-acetylpyridine with different concentrations $(0.1-10 \mathrm{mg} / \mathrm{L})$ and plotting the average peak areas as ordinate vs. the concentrations of each analyte as abscissa. Then, the concentration of 3-acetylpyridine in the samples (wt.\%) was determined from as-prepared calibration curve based on the detected peak area. The solubilities at a given pressure and temperature were determined by quantifying the amount 
Table 2

Experimental solubilities of 3-acetylpyridine in supercritical $\mathrm{CO}_{2}$ over the measurement range.

\begin{tabular}{|c|c|c|c|c|}
\hline \multirow[t]{2}{*}{$P(\mathrm{MPa})$} & \multicolumn{4}{|c|}{ Solubility $\left(\times 10^{-2}\right)\left(\mathrm{kg} / \mathrm{m}^{3}\right)$} \\
\hline & $313.15 \mathrm{~K}$ & $323.15 \mathrm{~K}$ & $333.15 \mathrm{~K}$ & $343.15 \mathrm{~K}$ \\
\hline 10 & $1.541 \pm 0.005$ & $1.152 \pm 0.013$ & $0.904 \pm 0.006$ & $0.69 \pm 0.012$ \\
\hline 12 & $1.915 \pm 0.009$ & $1.715 \pm 0.051$ & $1.473 \pm 0.022$ & $1.38 \pm 0.044$ \\
\hline 14 & $2.426 \pm 0.007$ & $2.683 \pm 0.049$ & $2.722 \pm 0.019$ & $2.93 \pm 0.036$ \\
\hline 16 & $2.790 \pm 0.004$ & $3.622 \pm 0.022$ & $4.258 \pm 0.022$ & $4.75 \pm 0.027$ \\
\hline 18 & $2.986 \pm 0.008$ & $4.416 \pm 0.008$ & $5.754 \pm 0.036$ & $7.03 \pm 0.006$ \\
\hline 20 & $3.593 \pm 0.044$ & $5.055 \pm 0.005$ & $7.116 \pm 0.018$ & $9.42 \pm 0.008$ \\
\hline 22 & $3.916 \pm 0.033$ & $6.041 \pm 0.036$ & $8.682 \pm 0.024$ & $11.37 \pm 0.018$ \\
\hline 24 & $4.717 \pm 0.008$ & $6.757 \pm 0.051$ & $9.824 \pm 0.053$ & $13.91 \pm 0.043$ \\
\hline 26 & $5.423 \pm 0.018$ & $7.754 \pm 0.044$ & $11.292 \pm 0.084$ & $16.19 \pm 0.055$ \\
\hline
\end{tabular}

of 3-acetylpyridine in ethanol for a given volume of $\mathrm{CO}_{2}$. All measurements were repeated three times at identical operational conditions and presented as mean \pm SD for three replicate determinations.

\section{Results and discussion}

\subsection{Solubilities of 3-acetylpyridine in supercritical carbon dioxide}

The quantity of a particular compound that can dissolve in a particular supercritical solvent to form a saturated supercritical phase strongly depends on the solvent density. In this regards, the densities of supercritical $\mathrm{CO}_{2}$ at various temperatures and pressures were estimated using Stryjek-Vera modification of Peng-Robinson (PRSV) equation of state and the results are given in Supplementary Material Table S1. The use of PRSV equation of state is generally superior to other equations for estimating the fluid densities of many materials in moderately non-ideal systems, typically nonpolar ones with relatively accurate correlation results [6]. Moreover, PRSV equation of state is convenient to use since it only requires the knowledge of critical properties and acentric factor for the generalized parameters and computationally efficient to solve this equation. The critical pressure, critical temperature, and acentric factor for carbon dioxide and 3-acetylpyridine is $7.39 \mathrm{MPa}$, $304.25 \mathrm{~K}, 0.225$ and $4.47 \mathrm{MPa}, 729.15 \mathrm{~K}$, and 0.464 , respectively. At isothermal condition (e.g., $313.15 \mathrm{~K}$ ), the increase of pressures from $10 \mathrm{MPa}$ to $20 \mathrm{MPa}$ causes the solvent power of the fluid to increase from $(1.541 \pm 0.005) \times 10^{-2} \mathrm{~kg} / \mathrm{m}^{3}$ to $(3.593 \pm 0.044) \times 10^{-2} \mathrm{~kg} / \mathrm{m}^{3}$. Similar trends were noticed in other three temperatures studied. The experimental solubilities of 3-acetylpyridine in $\mathrm{SC}-\mathrm{CO}_{2}$ over the measurement range were summarized in Table 2 . It can be seen that the solubilities increased at elevated pressures and temperatures, except those at two pressures of $12 \mathrm{MPa}$ and $14 \mathrm{MPa}$. It is clearly understandable that increasing pressure at a constant temperature enhances the solvent density, leading to increased amount of solute dissolved in the solvent phase. Meanwhile, the system temperature has different effects on solubility due to the influences of temperature on the vapor pressure, the density of supercritical solvent, and the molecular interaction of supercritical phase. Near the critical region of $\mathrm{CO}_{2}(304.25 \mathrm{~K}, 7.39 \mathrm{MPa})$, a small temperature rise from $313.15 \mathrm{~K}$ to $323.15 \mathrm{~K}$ at $10 \mathrm{MPa}$ may lead to a large fall in the solvent density $\left(565 \mathrm{~kg} / \mathrm{m}^{3}\right.$ to $\left.376 \mathrm{~kg} / \mathrm{m}^{3}\right)$ and a resulting change in 3-acetylpyridine solubilities $\left((1.541 \pm 0.005) \times 10^{-2}\right.$ to $\left.(1.152 \pm 0.013) \times 10^{-2} \mathrm{~kg} / \mathrm{m}^{3}\right)$. Increasing temperature would increase the solute's volatility and the diffusivities of both solvent and solute species, but cause the reduction in solvent capacity. These opposing effects resulted in the crossover phenomena in the solubility isotherms as illustrated in Fig. 2. The actual solubility data and regression models are designated as dot symbols and dashed lines, respectively. A near-linear relationship between pressure and mole fraction of 3-acetylpyridine in the mixture is obviously seen

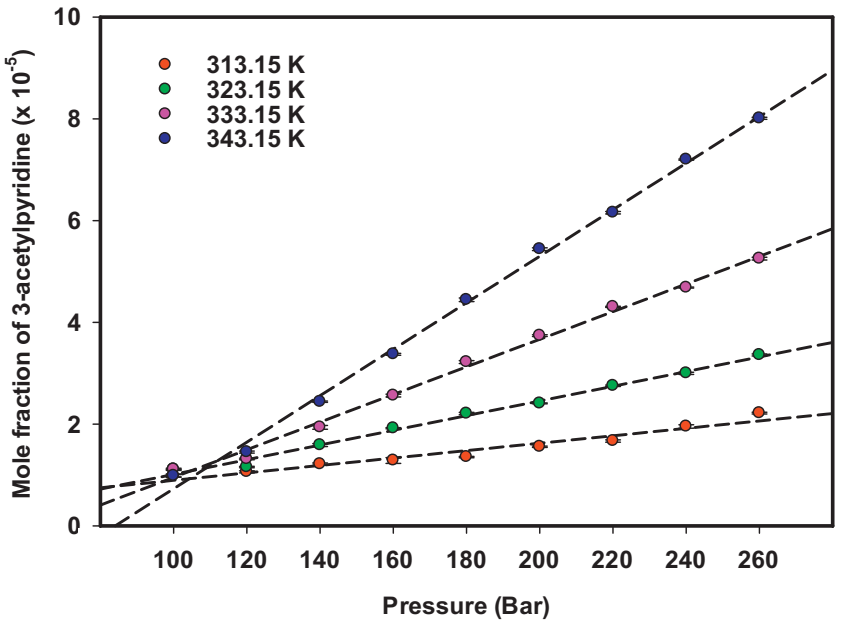

Fig. 2. Mole fraction of 3-acetylpyridine at various pressures and linear regression analysis (experimental data - dot symbols; regression model - dashed lines).

in this figure, with fairly small errors below $2 \%$. At pressures below the crossover point, the density effect dominates such that the solubilities decrease with temperature rise (referred as retrograde solubility behavior) [7]. On other hand, beyond the crossover pressure (in this system is $12 \mathrm{MPa}$ ), the solubilities of 3-acetylpyridine in supercritical $\mathrm{CO}_{2}$ increase both with solvent density and volatility effect in which the latter factor is more prominent.

\subsection{Semi-empirical density-based correlations}

Several mathematical models have been developed to date for correlating the solubility data of a particular compound in a particular supercritical solvent at various pressures and temperatures. Some of these correlation models are highly empirical while some of them have a strong fundamental theory with thermodynamics consideration. In the present work, the solubility data of 3-acetylpyridine in $\mathrm{SC}-\mathrm{CO}_{2}$ were correlated using semi-empirical density-dependent models and cubic equations of state for evaluating phase equilibria of the system. Chrastil and Del Valle and Aguilera mathematical models were used to correlate actual solubilities of 3-acetylpyridine in $\mathrm{SC}-\mathrm{CO}_{2}$ at studied pressures and temperatures. The main advantage of using density-based correlations such as Chrastil and Del Valle and Aguilera is they do not require any thermophysical properties such as critical point, acentric factor, vapor pressure, and molar volume of the studied compound [8], which often cannot be easily determined using experimental approach. Chrastil (1982) was the first who developed a semi-empirical equation by assuming the formation of solvato complex between solute and supercritical solvent at equilibrium $[9,10]$ :

$\mathrm{A}+k \mathrm{~B} \leftrightarrow(\mathrm{AB})_{k}$

where one molecule of solute A associates with $k$ molecules of supercritical solvent $B$ to form one molecule of solvato complex $(\mathrm{AB})_{k}$. Chrastil model has mathematical form as follows:

$y=\rho^{k} \exp \left(\frac{a}{T}+b\right)$

The adjustable constants $a$ and $b$ are defined as:

$a=\frac{\Delta H}{R}$

$b=-\ln \frac{M_{c}{ }^{k}}{M_{\mathrm{A}}+k M_{c}}+q$ 

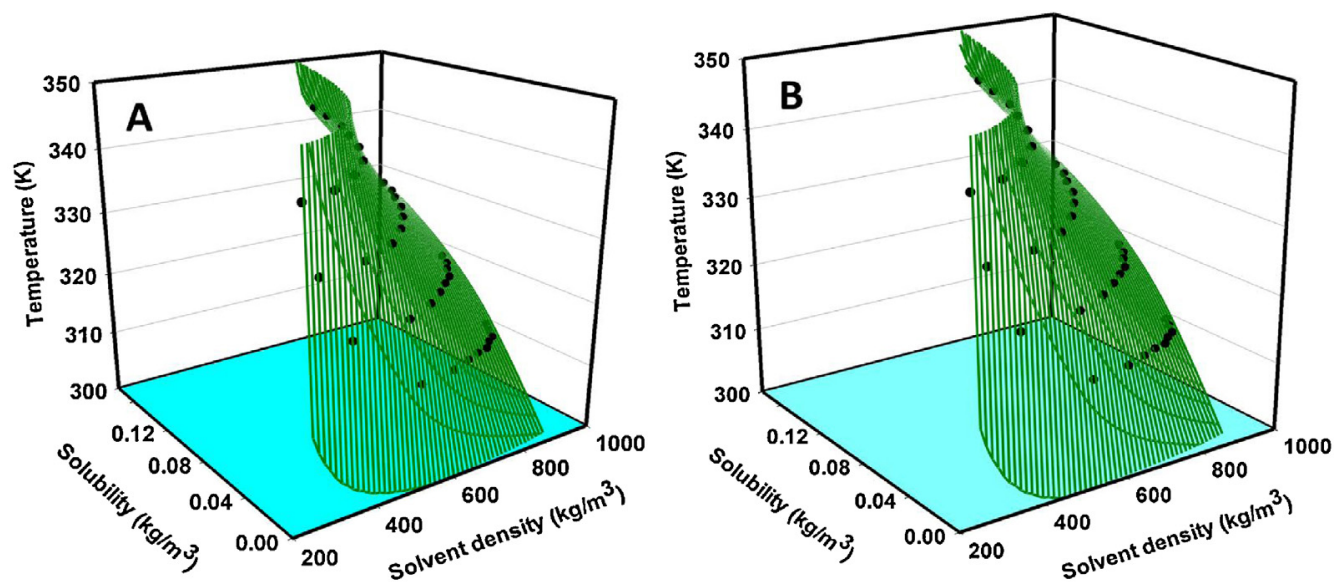

Fig. 3. Correlations of experimental solubilities of 3-acetylpyridine in supercritical $\mathrm{CO}_{2}$ (dot symbols) and those predicted with Chrastil (A) and Del Valle and Aguilera (B) mathematical models (wire-mesh).

where $y$ is the solubility $\left(\mathrm{kg} / \mathrm{m}^{3}\right), \rho$ is the solvent density $\left(\mathrm{kg} / \mathrm{m}^{3}\right), k$ is the average association number, $T$ is the absolute temperature $(\mathrm{K}), R$ is the universal gas constant $(8.314 \mathrm{~J} \mathrm{~mol} / \mathrm{K}), a$ is a function of enthalpy of solvation ( $\Delta H_{\text {solv }}$ ) and enthalpy of vaporization $\left(\Delta H_{\text {vap }}\right), b$ is a function of average association number that depends on the molecular mass of solute $\left(M_{\mathrm{A}}, 121.14 \mathrm{~g} / \mathrm{mol}\right)$ and supercritical solvent $\left(M_{c}, 44.01 \mathrm{~g} / \mathrm{mol}\right), \Delta H_{R}$ is total heat of reaction, which equals to the sum of enthalpy of solvation and enthalpy of vaporization, and $q$ is an adjustable constant.

The fitting of experimental solubility data was conducted concurrently at all temperatures using nonlinear least-squares regression technique with SigmaPlot software package (Version 12.3 , Systat Software Inc.) by minimizing root-mean-square deviation (RMSD):

$\operatorname{RMSD}=\left[\frac{\sum_{n=1}^{n}\left(y_{\text {exp }}-y_{\text {calc }}\right)^{2}}{N}\right]^{0.5}$

Here, $y_{\exp }$ is the actual solubilities, $y_{\text {calc }}$ is the calculated solubilities, and $N$ is the number of experimental data. The nonlinear least-squares regression technique involves an iterative curve fitting procedure to obtain the optimal parameter values that satisfy convergence and tolerance limit. A set of initial values of fitted parameters of the model (i.e., $a, b$, and $k$ ) was determined to start the computation. The number of iterations and step size was designed in such a way to reduce unnecessary computation without affecting the accuracy of predictions.

Fig. 3 clearly displays that Chrastil model can visually correlate experimental solubility data very well with root-mean-square deviation of 0.0027 . The optimal fitted parameter values are tabulated in Table 3. The adjustable parameter $k$ expresses an average equilibrium association number of which the values of this parameter are often not an integer based on the fact that the formation of solvato complexes not stoichiometrically takes place, with more or less stable solvato complexes [10]. The value of parameter $k$ obtained from Chrastil model fitting is 3.38 , which means that one molecule of 3-acetylpyridine associates with 3.38 molecules of supercritical $\mathrm{CO}_{2}$ to form one molecule of solvato complex at equilibrium state. Considering the value of adjustable constant $a$, total reaction heat of the dissolution process of 3-acetylpyridine in supercritical $\mathrm{CO}_{2}$ can be estimated to be $-56.10 \mathrm{~kJ} / \mathrm{mol}$. The negative value indicates that the dissolution process of 3-acetylpyridine in supercritical $\mathrm{CO}_{2}$ is exothermic in nature with greater magnitude of energy liberated from the associating process than that required to vaporize solute and solvent molecules by breaking intermolecular forces, characterizing a non-ideal fluid system.

Chrastil model has been intensively modified by a number of authors over past few years and one of them is Del Valle and Aguilera. Del Valle and Aguilera (1988) density-based model was chosen because this model compensates for the variation of solute's vaporizing heat with temperature [11]. Del Valle and Aguilera model has a mathematical form as follows:

$y=\rho^{k^{\prime}} \exp \left(b^{\prime}+\frac{a^{\prime}}{T}+\frac{d}{T^{2}}\right)$

$\Delta H=R\left(a^{\prime}+\frac{2 d^{\prime}}{T}\right)$

The adjustable parameters $k^{\prime}, b^{\prime}$, and $a^{\prime}$ have the same physical meaning to those of Chrastil model. The constant term $d^{\prime} / T^{2}$ is an adjustable parameter associated with the variation of solute's vaporization heat with temperature.

Fig. 4 shows that Del Valle and Aguilera model can represent experimental solubility data of 3-acetylpyridine in supercritical $\mathrm{CO}_{2}$ over the measurement range satisfactorily (RMSD of 0.0026). The optimal fitted parameter values of Del Valle and Aguilera model are presented in Table 3. From the values of adjustable parameters

Table 3

The fitted parameters of Chrastil and Del Valle and Aguilera models for correlating system supercritical $\mathrm{CO}_{2}$ (1)+3-acetylpyridine (2).

\begin{tabular}{|c|c|c|c|c|c|c|}
\hline \multirow[t]{2}{*}{ Model } & \multirow[t]{2}{*}{$T(\mathrm{~K})$} & \multicolumn{5}{|l|}{ Parameters } \\
\hline & & $a$ & $b$ & $k$ & $d$ & RMSD \\
\hline \multirow[t]{4}{*}{ Chrastil } & 313.15 & -6746.67 & -4.50 & 3.38 & - & 0.0027 \\
\hline & 323.15 & & & & & \\
\hline & 333.15 & & & & & \\
\hline & 343.15 & & & & & \\
\hline \multirow[t]{4}{*}{ Del Valle and Aguilera } & 313.15 & -16409.25 & 10.09 & 3.39 & $1.59 \times 10^{6}$ & 0.0026 \\
\hline & 323.15 & & & & & \\
\hline & 333.15 & & & & & \\
\hline & 343.15 & & & & & \\
\hline
\end{tabular}



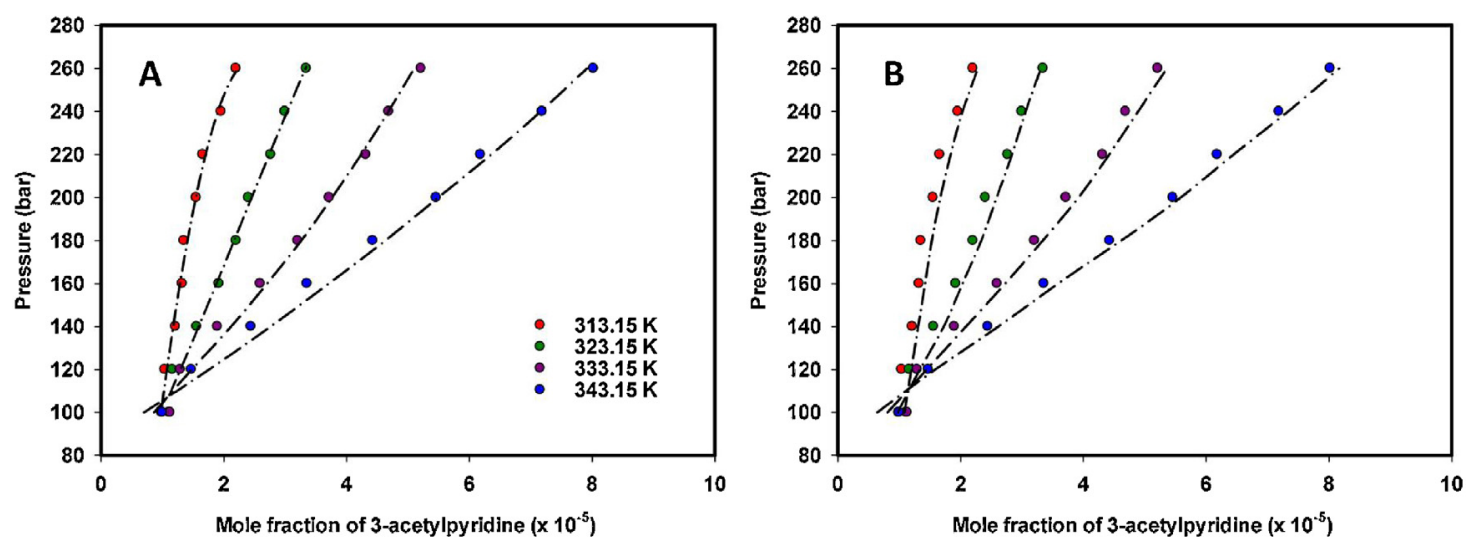

Fig. 4. Correlation results of mole fraction of 3-acetylpyridine at various pressures and temperatures with Peng-Robinson equation of state incorporated with quadratic (A) and Stryjek-Vera (B) mixing rules.

$a^{\prime}$ and $d^{\prime}$, one can estimate total reaction heat that ranges between $-51.76 \mathrm{~kJ} / \mathrm{mol}$ and $-59.16 \mathrm{~kJ} / \mathrm{mol}$. As aforementioned, Del Valle and Aguilera density-dependent model was developed based on the predecessor model (Chrastil equation) therefore this model should give a similar value of fitted parameters. The average association number obtained from Del Valle and Aguilera model fitting is comparable to that of Chrastil model, which means that both models are able to adequately describe the formation of solvato complex between 3-acetylpyridine and supercritical $\mathrm{CO}_{2}$ at equilibrium. By examining constant $b^{\prime}$, it was found that the calculated values of constant $q$ for Chrastil and Del Valle and Aguilera equations are considerably different (2.69 vs. 17.32 ).

\subsection{Phase equilibria evaluation using cubic equations of state}

A number of cubic equations of state with either an empirical, semi-empirical, or theoretical basis are available and have been widely used for phase equilibria evaluation of high-pressure systems and the most popularly used is Peng-Robinson equation of state. With this approach, the vapour-liquid coexistence or supercritical phenomena of a particular fluid mixture can be represented with single equation of state without any conceptual difficulties. However, it should be noted that the applicability of different equations of state is limited and generally accurate over certain measurement range for a particular system. Peng-Robinson equation of state has a mathematical form:

$P=\frac{R T}{V-b}-\frac{a(T)}{V^{2}+2 V b-b^{2}}$

where $P$ is the absolute pressure (atm), $T$ is the absolute temperature $(\mathrm{K}), V$ is the molar volume $(\mathrm{L} / \mathrm{mol})$, and $R$ is the gas constant $(8.314 \mathrm{~J} \mathrm{~mol} / \mathrm{K})$. The adjustable parameters $a$ and $b$ are both temperature-independent. For single compound system, the constants $a$ and $b$ can be determined using a series of equations as follows:

$a(T)=\alpha \cdot \alpha\left(T_{r}, \omega\right)$

$\alpha=0.4572 \frac{R^{2} T_{c}^{2}}{P_{c}}$

$\alpha\left(T_{r}, \omega\right)=\left(1+\kappa\left(1-\sqrt{T_{r}}\right)\right)^{2}$

$\kappa=0.3746+1.5422 \omega-0.2692 \omega^{2}$

$b=0.0778 \frac{R T_{c}}{P_{c}}$

where $P_{c}, T_{c}, \omega$, and $\kappa$ are critical pressure (MPa), critical temperature $(\mathrm{K})$, acentric factor, and adjustable parameter characteristic for each compound, respectively. The critical properties $\left(T_{c}\right.$ and $\left.P_{c}\right)$ and acentric factor $(\omega)$ of 3-acetylpyridine were predicted using the Joback and Lee-Kesler group contribution methods, respectively with PE2000 computational software (Version 2.9.9a). The prediction of critical pressure and critical temperature using Joback method is simply performed by inputting the number of each functional group and normal boiling point of the compound. This group contribution method has found reasonable accuracy in predicting the critical properties of large variety of compounds [12,13]. Once the critical pressure and critical temperature are obtained, the acentric factor of the compound can be easily determined. To correlate vapour-liquid equilibria of multicomponent systems, appropriate mixing and combining rules should be directly integrated into equations of state parameters. In this regards, both parameters $a$ and $b$ of Peng-Robinson equation of state can be expressed in the form of classical van der Waals mixing rule, as shown below [14-16]:

$a=\sum_{i=1}^{\mathrm{N}} \sum_{j=1}^{\mathrm{N}} x_{i} x_{j} a_{i j}$

$b=\sum_{i=1}^{\mathrm{N}} \sum_{j=1}^{\mathrm{N}} x_{i} x_{j} b_{i j}$

In this work, two frequently used mixing rules namely quadratic and Stryjek-Vera (SV) mixing rules were employed for correlating phase equilibrium behavior of 3-acetylpyridine in supercritical $\mathrm{CO}_{2}$ over the measurement range. The adjustable parameters $a_{i j}$ and $b_{i j}$ for quadratic mixing rule can be written in the following mathematical forms $[3,9,16]$ :

$a_{i j}=\sqrt{a_{i i} a_{j j}}\left(1-k_{i j}\right) \quad$ with $k_{j i}=k_{i j}$

$b_{i j}=\frac{b_{i i}+b_{j j}}{2}\left(1-l_{i j}\right) \quad$ with $l_{j i}=l_{i j}$

while for Stryjek-Vera mixing rule, the constants $a$ and $b$ are given as follows [17]:

$a_{i j}=\sqrt{a_{i i} a_{j j}}\left[1-\frac{k_{i j} k_{j i}}{x_{i} k_{i j}+x_{j} k_{j i}}\right] \quad$ with $k_{j i} \neq k_{i j}$

$b_{i j}=\frac{b_{i i}+b_{j j}}{2}\left(1-l_{i j}\right) \quad$ with $l_{j i}=l_{i j}$

$k_{j i}=k_{i j}-\lambda_{i j}$

where $k_{i j}$, $k_{j i}$, and $l_{i j}$ are all binary interaction parameters and can be determined by iterative curve fitting procedure of experimental data. For this purpose, PE2000 software was applied to obtain 
Table 4

Optimal values of binary interaction parameters of Peng-Robinson equation of state incorporated with quadratic and Stryjek-Vera mixing rules.

\begin{tabular}{lllrlll}
\hline Mixing rules & $T(\mathrm{~K})$ & \multicolumn{6}{c}{ Binary interaction parameters } & \multirow{2}{*}{ RMSD } \\
\cline { 3 - 6 } & & $k_{i j}$ & \multicolumn{1}{c}{$l_{i j}$} & \multicolumn{1}{l}{$k_{j i}$} & \multicolumn{1}{c}{$\lambda_{i j}$} & \\
\hline Quadratic & 313.15 & 0.544 & -0.013 & - & - & 0.084 \\
& 323.15 & 0.621 & 0.016 & - & - & 0.071 \\
& 333.15 & 0.739 & 0.037 & - & - & 0.060 \\
\multirow{2}{*}{ Stryjek-Vera } & 343.15 & 0.932 & 0.115 & - & - & 0.051 \\
& 313.15 & 0.816 & 0.090 & 0.578 & 0.238 & 0.084 \\
& 323.15 & 0.521 & -0.025 & 0.608 & -0.087 & 0.075 \\
& 333.15 & 0.786 & 0.057 & 1.479 & -0.693 & 0.062 \\
& 343.15 & 0.568 & -0.029 & 0.901 & -0.333 & 0.053 \\
\hline
\end{tabular}

the optimal values of fitted binary interaction parameters by minimizing objective function and satisfying convergence. The optimal values of binary interaction parameters of Peng-Robinson equation of state incorporated with quadratic and Stryjek-Vera mixing rules are tabulated in Table 4.

Fig. 4 displays the correlation results between predicted and experimental solubility data of 3-acetylpyridine in supercritical $\mathrm{CO}_{2}$ using Peng-Robinson equation of state with quadratic and Stryjek-Vera mixing rules. The root-mean-square deviation between actual and predicted values was in the range of 0.051 to 0.084 for quadratic mixing rule, which is comparable with Stryjek-Vera mixing rule. The interaction parameter values of $k_{i j}$ and $l_{i j}$ for quadratic mixing rule (Table 4) increase at higher temperature. This result indicates that higher temperature facilitates interaction between "like" molecules, for example solute-supercritical solvent interaction to form a solvato complex. On other hand, the values of binary parameters $k_{i j}, l_{i j}$, and $\lambda_{i j}$ for Stryjek-Vera mixing rule show inconsistency with temperature variation. The value of $k_{j i}$ at temperature of $333.15 \mathrm{~K}$ is larger than unity, which gives the values of $a$ and $a_{i j}$ less than zero. Regardless of similarity of RMSD values, it can be deduced that Peng-Robinson equation of state incorporated with quadratic mixing rule is superior and more sensitive in describing the dependency of binary interaction parameters with temperature than PR-EoS incorporated with Stryjek-Vera mixing rule.

\section{Conclusions}

New solubility data of 3-acetylpyridine in supercritical carbon dioxide over wide range of pressures and temperatures have experimentally measured in this work under static mode. The crossover phenomenon was observed at pressure of $12 \mathrm{MPa}$ and the solubilities of solute in supercritical solvent increased with increasing both pressure and temperature of the system. For mathematical modeling, semi-empirical density-dependent equations namely Chrastil and Del Valle and Aguilera equations gave satisfactory agreement for solubilities correlation over the measurement range. The exothermicity nature of associating process and the equilibrium formation of solvato complexes between 3-acetylpyridine and supercritical carbon dioxide could be consistently described by both equations. The evaluation of phase equilibria of supercritical system using Peng-Robinson equation of state incorporated with quadratic mixing rule show that temperature was the influential factor toward adjustable binary interaction parameters while PREoS incorporated with Stryjek-Vera mixing rule failed to describe this behavior.

\section{Acknowledgment}

The first author (Bely Agustin) would like to express her sincere gratitude to Department of Chemical Engineering, National Taiwan University of Science and Technology for undergraduate exchange student grant and provision of all research facilities.

\section{Appendix A. Supplementary data}

Supplementary material related to this article can be found, in the online version, at http://dx.doi.org/10.1016/j.fluid.2013.06.036.

\section{References}

[1] J.A. Maga, J. Agric. Food Chem. 29 (1981) 895-898.

[2] T.E. Kinlin, R. Muralidhara, A.O. Pittet, A. Sanderson, J.P. Walradt, J. Agric. Food Chem. 20 (1972) 1021-1028.

[3] M. Richter, H. Sovova, Fluid Phase Equilib. 85 (1993) 285-300.

[4] D.E. Knox, Pure Appl. Chem. 77 (2005) 513-530.

[5] N.P. Kulshreshtha, S.C. Moldoveanu, J. Chromatogr. A 985 (2003) 303-312.

[6] S.I. Sandler, Chemical and Engineering Thermodynamics, third ed., Wiley, New York, 1999.

[7] Ö. Güçlü-Üstündag, F. Temelli, J. Supercrit. Fluids 31 (2004) 235-253.

[8] D.L. Sparks, R. Hernandez, L.A. Estevez, Chem. Eng. Sci. 63 (2008) 4292-4301.

[9] P. Subra, S. Castellani, H. Ksibi, Y. Garrabos, Fluid Phase Equilib. 131 (1997) 269-286.

[10] J. Chrastil, J. Phys. Chem. 86 (1982) 3016-3021.

[11] J.M. Del Valle, J.M. Aguilera, Ind. Eng. Chem. Res. 27 (1988) 1551-1553.

[12] K.G. Joback, R.C. Reid, Chem. Eng. Commun. 57 (1987) 233-243.

[13] B.E. Poling, J.M. Prausnitz, J.P. O'Connell, The Properties of Gases and Liquids, fifth ed., McGraw-Hill Co., New York, 1987.

[14] K.K. Liong, N.R. Foster, S.S.T. Ting, Ind. Eng. Chem. Res. 31 (1992) 400-404.

[15] S. Ismadji, J. Chem. Eng. Data 53 (2008) 2207-2210.

[16] P. Coimbra, M.R. Blanco, H.S.R.C. Silva, M.H. Gil, H.C. de Sousa, J. Chem. Eng. Data 51 (2006) 1097-1104.

[17] R. Stryjek, J.H. Vera, Can. J. Chem. Eng. 64 (1986) 820-826. 